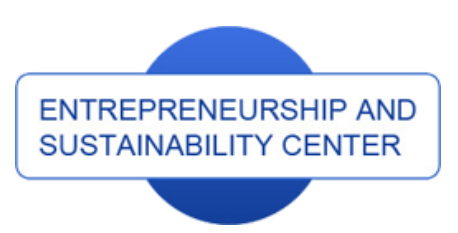

Publisher

http://jssidoi.org/esc/home

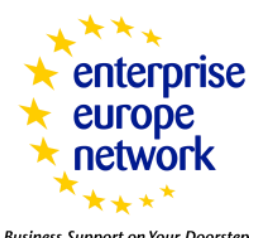

Business Support on Your Doorstep

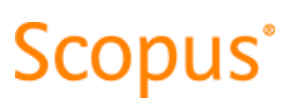

\title{
SOCIO-SPATIAL DYNAMICS, NETWORKS AND MODELLING OF REGIONAL MILIEU*
}

\author{
Andrey S. Mikhaylov \\ Immanuel Kant Baltic Federal University, Institute of Environmental Management, Urban Development and Spatial \\ Planning, A. Nevskogo str. 14, 236016, Kaliningrad, Russian Federation \\ E-mails: mikhailov.andrey@yahoo.com
}

Received 15 March 2018; accepted 10 June 2018; published 30 June 2018

\begin{abstract}
Spatial networking is the 'new normality' of local innovation systems, featuring a heterogeneous set of inter-organizational ties and a constant circulation of information, knowledge, practices, and other intangible assets of actors engaged in the regional innovation milieu. Understanding the particularities of territorial communities formed clarify the socio-spatial dynamics and the development trajectory of the region, its competitiveness and innovative potential. The study explores the variety of factors that affect the patterns of these socio-economic interactions, such as the networking objectives, the stakeholders involved, the benefits projected, their spatial embeddedness, as to reduce the equivocality inherent to methodologies of delimitation and subsequent demarcation of spatial-network interactions. The study rests upon analysis of different types of relations formed between heterogeneous actors of regional socio-economic system, both at inter-firm and inter-organizational level. Providing a classification of major factors that determine the features and patterns of spatial networking, the paper proceeds with discussing the differences in their dynamic configurations using three scholarly concepts industrial district, business cluster, and global innovation network. The study revealed 20 individual typological characteristics in a group of four determining features of spatial-network interactions - the stakeholders, the linkages, the network, and the context. The typology elaborated is irrelative to the types of spatial networking analyzed, thus, being equally applicable to the modeling of different configurations of entrepreneurial interactions within the regional milieu. Territorial capital assessment requires a holistic approach in determining the socio-spatial dynamics of the regional milieu. This necessitates defragmentation of local ties into value constellations of the single regional socio-economic and innovation system. The study contributes to the understanding of internal mechanisms of various forms of entrepreneurial networking, providing a set of criteria for integrated evaluation of spatial-network interactions.
\end{abstract}

Keywords: spatial dynamics, regional milieu, local networks, territorial capital

Reference Mikhaylov, A.S. 2018. Socio-spatial dynamics, networks and modelling of regional milieu, Entrepreneurship and Sustainability Issues 5(4): 1020-1030. http://doi.org/10.9770/jesi.2018.5.4(22)

\footnotetext{
* The reported study was funded by RFBR according to the research project 18-010-00015 "Models, effects, strategies and mechanisms of the inclusion of the western borderline of Russia into the system of horizontal interregional economic relations in the context of the Greater Eurasia"
} 


\section{Introduction}

Regional ecosystem is a mosaic of a unique set of resources and infrastructures (industrial, social, transport, engineering, information, innovation, etc.) characterized by the individual institutional architecture of the territorial socio-economic system that acts as a medium for the formation and functioning of various forms of entrepreneurial networking. Spatially rooted milieu of inter-organizational interrelations and bonds between the subjects of the regional innovation system implies a dynamic 'value constellations' (Normann \& Ramirez, 1993) complex of horizontally and vertically integrated actors who represent various institutional helices (business, scientific and educational institutions, governmental bodies and authorities, public associations, other types of non-profit organizations) and are united by their attributive similarities and the commonality of individual aspirations. The combination of complementary competences of stakeholders (including their intangible assets; Teece, 1998; 2007), their quasi-integration (vertical, horizontal, oblique; Leborgne \& Lipietz, 1988; 1992) achieved in the course of sustainable formal and informal network links has a fundamental influence on the transformation of the geo-economic context and the trajectory its further development.

Recognizing this interdependence, the contemporary policies on regional socio-economic and innovative development are increasingly associated with the territorial capital assessment (Camagni, 2017; Capello et al., 2011; Perucca, 2014; Toth, 2014). First introduced in the report of the Organization for Economic Cooperation and Development (OECD) in 2001, the territorial capital perspective emphasizes the need of taking into account the specific features of the territories when formulating the regional development policies. In analytical terms this implied disaggregation of the regional milieu into numerous 'inclusions' - spatial networks (e.g. clusters, industrial spaces, technological districts, etc.; see Mikhaylov \& Bolychev, 2015) that are rooted in a geographically outlined territorial system (industrial zone, part of the urban agglomeration, city, rural settlement, municipal district, administrative and territorial formation, etc.). These local communities based on common practice (Brown \& Duguid, 1991), shared knowledge (Breschi \& Lissoni, 2001; Capello, 1999; Cohen \& Levinthal, 1990; Lane \& Lubatkin, 1998; Tallman et al., 2004), or other proximities (Boschma, 2005; Knoben \& Oerlemans, 2006; Mattes, 2011; Torre \& Gilly, 2000; Torre \& Wallet, 2014) form synergies and emergent effects in determining the identity and unique properties of the geospace. The identification of such organizational, institutional, socio-cultural, technological and other intangible coherence of actors plays a key role in the assessment of territorial capital, the competitiveness of the region, its innovative potential. Awareness of the regularities and patterns in the formation of territorial communities enriches the in-depth understanding of regional divergence phenomenon and enables targeted reproduction of the growth node practices within customized regional policies.

\section{Literature review}

According to the provisions of the actor-network theory (Murdoch, 1998), the interactions of economic entities within the boundaries of the regional ecosystem are characterized by processes of direct and indirect influence on one another and the network environment as a whole, with each of the interacting parties being the cause and effect of the simultaneous reverse influence of the counterpart. Mutual conditionality of actors, generated by their involvement in a network of interactions, contributes to the distribution of roles in-between the network and ensures the filling of its 'structural holes' (Ahuja, 20001; Hite \& Hesterly, 2001; Zaheer \& Bell, 2005) - gaps in the network structure. Interactions are an integrating factor for network nodes relative to their competencies, 
providing functional defragmentation of individual elements in a certain type of integrity - the form of spatialnetwork interactions (industrial district, cluster, technology pole, etc.; Mikhaylov, 2016).

The integration of network interactions into the space of the territorial socio-economic system presupposes going beyond the limits of transactional relations, strengthening the significance of non-commercial ('untraded'; Storper, 1995) interdependencies and interpersonal relationships ('weak ties'; Granovetter, 1973). Involvement of representatives of various institutional helices in the processes of spatial-network interactions determines the breadth and variability of the combinations of relations that are formed between the network stakeholders. Their diversity are being formulated in the models of triple (Etzkowitz \& Leydesdorff, 2000), quadruple (Carayannis \& Campbell, 2009), quintuple (Carayannis \& Campbell, 2010; Carayannis \& Rakhmatullin, 2014) helices. The types of interactions being formed are characterized by:

- involvement in the processes of design, development and production (for example, collaboration, provision, complicity);

- information exchange, communication of knowledge (e.g., learning, examining, exploring);

- coherence and coordination of actions regarding intranet processes and the external environment (e.g., strategic partnership, fellowship, association);

- focus on mutual support, which does not involve direct commercial benefits (e.g., assistance, support, facilitation, reciprocity);

- rivalry within the boundaries of individual stages of the innovation process and the struggle for resources (e.g., competition, co-opetition);

- correlation of operational activities and strategic planning with respect to both individual and networkwide development trajectory (e.g., conjugation, coordination).

The presence of institutional, social, cultural, organizational, technological, cognitive intersection points (i.e. common grounds) at the inter-organizational level is correlated with the similarities (or 'closeness'; Gertler, 1995) of certain properties and functions of elements of the network of interactions. From the privision of classical economic theory the similarities considered are expressed in the dyadic inter-firm production relations of the model of inter-industry input-output tables (Leontief, 1973) - i.e. the value chain. With the broadening of the understanding of the nonlinearity and openness of the innovation process of the knowledge economy (Mikhaylova \& Mikhaylov, 2016), inter-organizational interactions are increasingly being interpreted through non-hierarchical connections of heterogeneous entities. The interactions of dissimilar actors that possess a different knowledge base, set of competencies, employment but complementary in the context of individual elements of the innovation process are found to be the most significant source of radical innovations, forming the inalienable competitive advantages of the network and the territorial capital of the region, thus, being the focal point of competitiveness of the regional innovation system.

A society acts as a catalyst for spatial-network interactions between both business entities (B2B) and between legal entities and the end user (B2C). The unmet market needs generate demand for a set of value propositions embodied in goods and services that satisfy the current and future needs of a certain category of people. Development and, most importantly, commercialization and distribution of innovative products and solutions is the key task of business, which is the central element of spatial-network interactions - the core of the concentric waves of the network that initiates and bonds the totality of stakeholders. In the process of spatial networking, there is a continuous transfer of products - goods, material resources, products and other tangible objects; services, including non-profit and public services; and information, both in its explicit (e.g. documents, procedures, standards) and implicit (e.g. ideas, skills, competencies, experience, best practices, organizational culture) forms. 
The nature and structure of spatial networking is uneven due to differences between interacting actors and the objectives pursued. Inter-firm interactions tend to build linear hierarchical links in the form of a value chain, in which duplication of company's functions represented in a particular market segment is excluded. Thus, the intranetwork competition is minimized. Unification of direct competitors generally takes place for a certain period of time (including the phenomenon of 'temporal clustering'; Torre, 2008) around large-scale resource- and knowledge-intensive projects or in response to external threats (e.g. in the pursuit to combat external competitors in the domestic market, respond to crisis phenomena or drastic changes in business conditions, etc.). Creation of strategic partnerships, coalitions, alliances and other associations except for the above is realized in cases of penetrating foreign markets in order to reduce risks and costs (e.g. via economies of scale); lobbying the interests of the industry in communication with government authorities; creation of common norms, rules, business culture as to facilitate further work within the network and with third-party organizations (e.g., implementation of international financial and quality standards, personnel policy criteria, etc.), and a number of other reasons.

Interaction of business entities with academia relates, above all, with the objectives to meet the needs for qualified personnel of the appropriate training profile. In this regard, companies conduct a dialogue on the content of the curriculum; provide scholarships for targeted training; participate in student training through the establishment of internship platforms, resource centers and the provision of on-site training for students. Other activities include realization of the scientific and technological (S\&T) potential of universities and academic institutions. Companies finance research of fundamental and applied nature, production of prototypes, laboratory testing, and the creation of their own laboratories based on HEIs grounds with the involvement of researchers to implement long-term projects. With the introduction of centers for collective use in the science and technology parks of universities, companies are involved in the joint use of the technical and laboratory facilities. Companies provide commercialization and transfer of technologies through the use of intellectual property; purchase of license agreements; the redemption of patents; creation of joint projects with the university start-ups and small innovative enterprises, supporting the implementation of entrepreneurial university concept.

The interaction of economic entities with state authorities is aimed at developing consolidated decisions on the necessary measures to support entrepreneurial, investment, innovation, export and internationalization activities, foster modernization of fixed assets and production facilities. State infrastructural projects for the creation of industrial zones, science and technology parks (incl. the highly focused ones, e.g. information technology, biotechnology, etc.), business incubators, technology transfer centers, exhibition and conference centers, etc. are of great importance. Public-private partnership is a common form of solving socially significant tasks. The position of the state as a mediator in the relationship between business and society is expressed in the legal regulation of labor relations; development and implementation of technological, environmental and other standards; monitor of the compliance with established rules and norms; support of non-state organizations and the promotion of their economic activity, etc.

\section{Research design and methodology}

Network interactions that form between actors in the geospace are distinguished by a significant variety of relations, which is caused by a large number of factors and conditions. The uniqueness of the properties of actors and the contextual environment in which they function contribute to the fact that the same types of interactions (competition, cooperation, collaboration, etc.) are realized in different ways. In this regard, regional interactive milieu will be analyzed against a number of spatial-network interaction types. The main factors are classified into four groups (figure 1): 
- the stakeholders: defining the characteristics of the network participants (sectoral and organizational affiliation) and the focus of their interests (goals, priorities, specialization);

- the linkages: determining the nature of relationships between the interacting parties (strength, consistency, objectives, formalization, hierarchy, numbers of connected elements);

- the network: reflecting the participation of the entity in the system of interactions (openness, systemic);

- the context: defining the features of spatial ties (rootedness, linearity, interactivity).

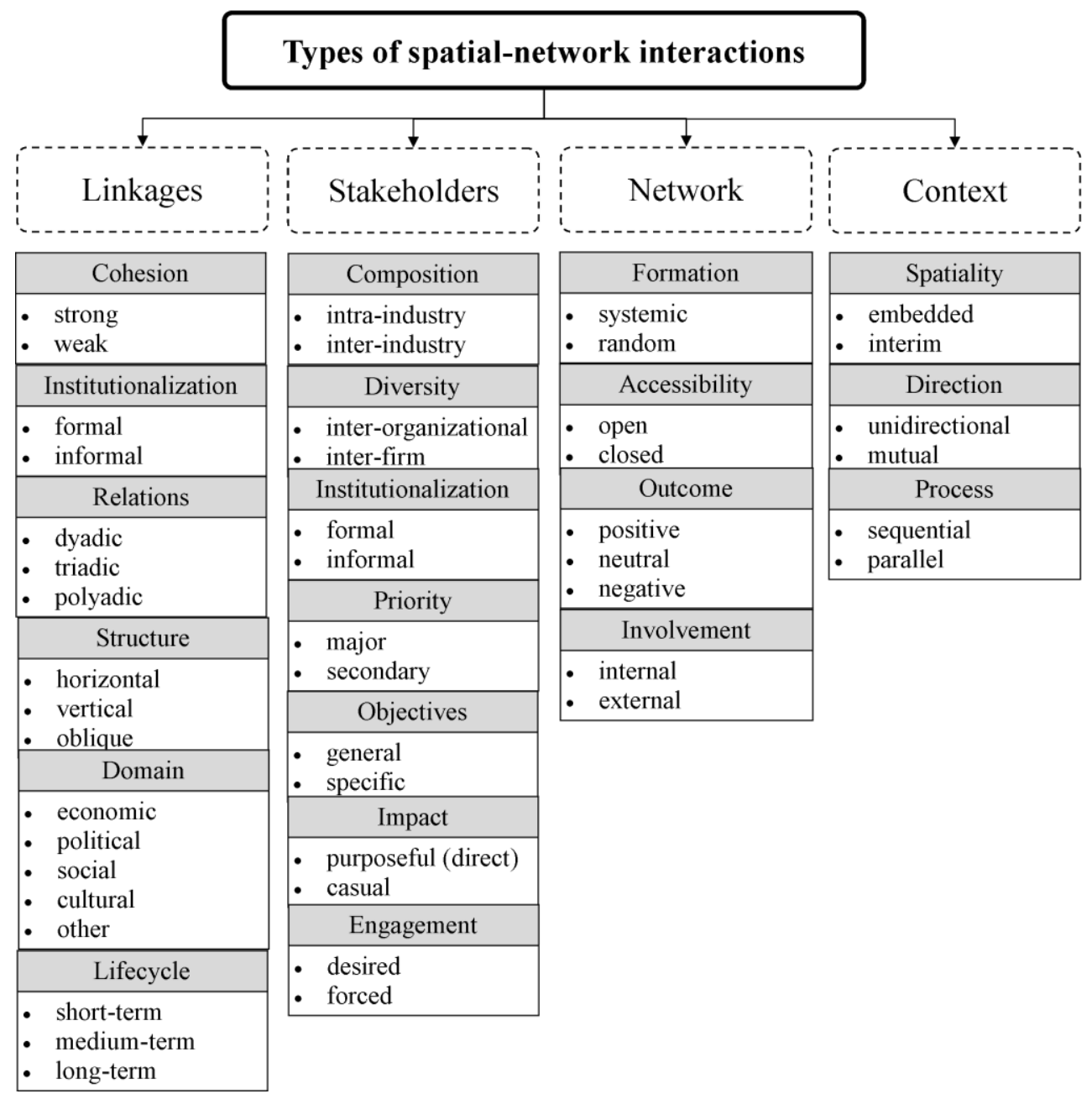

Fig.1. The types of spatial networking

The conceptual basis of the complex structure of spatial-network interactions applied is reflected in the "uneasy triangle of three C' - competition, collaboration and cooperation (Polenske. 2004). The study is designed inline with D'Aspremont and Jacquemin (1988), who cinsider competition as the primary type of interaction, which subsequently acts as a catalyst for the formation of creative ties - cooperation, and a more comprehensive type collaboration. The different types of inter-firm and inter-organizational relations between heterogeneous actors of regional socio-economic system identified are to be applied for analyzing socio-spatial interactions of different forms - industrial district, business cluster, and global innovation network. The three different forms of 
networking applied in the study enable to determine particularities in dynamic configurations of interactions in the regional milieu.

\section{Findings and Discussions}

\subsection{Spatial entrepreneurial networking as an integrating factor of regional interactive milieu}

Competition is a type of interaction that arises from the similarity of entities (usually in terms of outputs - goods, services, but also in attributive characteristics - employment, location, etc.) in case of the collision of their interests in the short, medium or long term. It facilitates intra-firm resource mobilization, modernization, innovation, and creates dynamism in the development of the economy. The absence or substantial restriction of competition with the formation of oligopolistic and monopolistic systems leads to stagnant phenomena and, subsequently, a decrease in the comparative efficiency of the use of production factors. Competitive relations are the most important mechanism for self-regulation of the economy, stimulating the growth of competitiveness, increasing the efficiency of economic processes (including cost reduction against the background of quality improvement), accelerating scientific, technological and innovative development. High competition is the most progressive type, when business entities are forced to implement strategic innovative projects, develop and implement innovative solutions, produce innovative products in order to remain successful (i.e. profitable) over a long-term period.

Interactions on the basis of cooperation in their essence are the answer to competition and pursue the goal of increasing the competitiveness of participants due to their complementarity. Cooperation can be realized both in the form of dyadic ties and network links, including a wide range of actors from different institutional spheres. Cooperative ties generally presuppose the joint realization of one or several interrelated processes by small and medium-sized business entities. It can be cooperation on secondary tasks, outsourcing, non-exclusive supply, information exchange, voluntary mutual assistance with regard to managerial decisions and training, technological cooperation for the implementation of a joint project, etc. In the short term, the basis of cooperative relations is often the social community, which has no formal consolidation. Long-term cooperation is more mature and involves the formation of stable, often formalized relationships (e.g. association, union). The implementation of cooperation on a systematic basis leads to the embeddedness of ties in the territorial system. According to Fombrun (1982) and Burt (2000), the spatially rooted links are more durable and stable, often bringing small firms together. Vertical and horizontal cooperative relations are distinguished. Vertical cooperation unites economic agents with a different but coherent set of functional roles; horizontal, on the contrary, is the cooperation of similar entities with identical functions. The result of cooperation is generally connected with the extraction of benefits by all interacting participants. A high level of cooperation and communication has a positive effect on innovation activity (Arndt \& Sternberg, 2000; Freel, 2003). In a number of cases, the emergence of cooperative relations is forced. A striking example is the links that form in the regional cluster, when competing companies work together to improve competitiveness and solve common problems. Such interactions are called 'co-opetition' (Gnyawali \& Park, 2009; Gnyawali \& Park, 2011; Lechner \& Dowling, 2003).

Collaboration is a more complex form of partnership than cooperation, presupposing a sustainable purposeful interaction of two or more actors in the design, production, and promotion of the product or process. Forming collaborations requires a long time and a certain level of trust, representing a complex process of internal restructuring of companies in order to maximize synchronization of actions and ensure consistency that goes beyond the scope of formal agreements. Collaboration results in strong systemic links both sectoral and intersectoral (i.e. inter-industry), being established with a high degree of formalization. An example of collaborative relationships is the outsourcing of elements of a key production or innovation process. Collaboration of economic entities implies their quasi-integration with the establishment of close inter-firm links of three types 
(Leborgne \& Lipietz, 1988): vertical, when the buyer has access to the know-how of the supplier; horizontal, expressed in a partnership for the division of labor within a certain technology; oblique, involving the outsourcing of part of the production process while maintaining the overall responsibility before the customer (e.g. in terms of final product quality).

\subsection{The configuration of interactions in various forms of spatial networking}

One of the most known forms of spatial networking is the classical industrial district, otherwise referred to as the 'Marshallian cluster' (Rugman \& Verbeke, 2003), being the historically conditioned agglomeration of small industrial companies clustered in small towns and rural settlements, engaged in utilizing their activities in traditional or craft industries and inter-connected on the basis of product specialization. The company's involvement in the district is expressed through the actual localization of production and the integration of employees into the local community, which has a historically formed identity in the light of a certain economic specialization. The absence of formal barriers for new companies is accompanied by a social confrontation, aimed at driving out the 'newcomer' through unfair competition and 'social blocking'.

Intra-regional cooperation between firms involved in mutually complementary production processes represents a 'system of interacting parts' (Amin, 1989). The consolidation and retention of companies occurs, mainly, at the expense of interpersonal contacts - friendship, kinship, in which the commonality of social culture (Bianchi, 1998) and professional practices (Lave \& Wenger, 1991) play a predominant role. Inter-firm interactions of industrial district are largely defined by the high geographical concentration of companies (e.g., street merchants, brewery districts, textile neighborhood) and the population (a significant number of companies represent family businesses). Most of the entrepreneurial interactions are negative (in economic terms) due to the continuous process of copying the best practices of the 'neighbor', including technologies and product range, management and marketing solutions. Cooperation is minimal and takes the form of semi-conscious, semi-voluntary coordination at the horizontal level (e.g. within respect to the local pricing system). The lack of a clear hierarchical structure makes it difficult for the collaboration to occur (e.g. to introduce technological innovations).

Business cluster interactions of regional actors implies not only the presence of large companies, but also the involvement of representatives of the scientific, educational and non-profit sector, which fundamentally changes the structure of interactions. Inter-sectoral inter-organizational interconnections of cluster actors presumes going beyond a narrow branch specialization, being characterized by a combination of formal (i.e. transaction) and informal (i.e. social) relations with the tendency towards the former. Regional clusters do not display same strong connection between society and business as the industrial districts do; the interactions are of an intra-system nature, being formed on the basis of the desire of its participants for mutually beneficial partnership and coherence. Targeted and sustainable internal communications are based on long-term strategic cooperation and collaboration, the advantages of which outweigh the benefits of competition. External interactions are casual. Opportunities of cooperation for external actors with the representatives of the cluster are fully open, but there are certain entry barriers: the accepted technological standards, the delivery system, the quality system, and other indicators of proximity dimensions.

Global innovation networks are also built on the principle of inter-organizational interactions without an explicit link to a particular industry. This form of spatial-network interactions is a conditionally open system. The integration of new participants is difficult, since it requires not only compliance with the network's common goals and objectives (i.e. mutual benefit), but also a certain high level of competence development among actors. Each of the interacting members has a clear leadership in a certain sphere of activity (i.e. global level of quality) and is interesting to others due to its inalienable competitive advantages. The reason for integrating small and mediumsized enterprises into global innovation networks is the availability of advanced technologies, the know-how, 
The International Journal

ENTREPRENEURSHIP AND SUSTAINABILITY ISSUES

ISSN 2345-0282 (online) http://jssidoi.org/jesi/

2018 Volume 5 Number 4 (June)

http://doi.org/10.9770/jesi.2018.5.4(22)

commercialization of which requires large capital investments, incl. in the creation of industrial designs, testing, licensing, etc. Interactions within global innovation networks are of a mutually beneficial nature and are implemented on a sustainable long-term basis.

\section{Conclusion}

Regional socio-economic and innovation ecosystem is characterized by a variety of forms of spatial-network interactions that are formed taking into account the specifics of contextual conditions, including the factor of location, and the aggregate of actors that have the potential of gaining mutual benefits using complementarities and intra-network 'related variety' (Frenken et al., 2007). The presented classification of the types of spatialnetwork interactions arising between actors in geospace reflects the dynamic variety of connections that transform under the influence of a wide range of factors and conditions. Inter-firm interactions tend to build a linear-hierarchical system of interacting elements involved in mutually complementary production processes. The interorganizational coherence of heterogeneous actors representing different institutional spheres (universitybusiness-government-society) can cover the widest range of relationships, including collaboration and quasiintegration of actors. Understanding the relationship between the types and forms of spatial-network interactions makes it possible to reduce the likelihood of discrepancies present in the implementation of existing methodological approaches to delimitation and subsequent demarcation of spatial-network interactions, increasing the efficiency of regional economic, industrial and innovation policies.

\section{References}

Ahuja, G. (2000). Collaboration networks, structural holes, and innovation: A longitudinal study. Administrative Science Quarterly, 45(3), 425-455. https://doi.org/10.2307/2667105

Amin, A. (1989). Flexible specialisation and small firms in Italy: myths and realities. Antipode, 21(1), 13-34. https://doi.org/10.1111/j.1467-8330.1989.tb00177.x

Arndt, O., \& Sternberg, R. (2000). Do manufacturing firms profit from intra-regional innovation linkages? An empirical-based answer. European Planning Studies, 8(4), 465-485. https://doi.org/10.1080/713666423

Bianchi, G. (1998). Requiem for the Third Italy? Rise and fall of a too successful concept. Entrepreneurship and Regional Development, 10(2), 93-116. https://doi.org/10.1080/08985629800000006

Boschma, R. (2005). Proximity and innovation: a critical assessment. Regional Studies, 39(1), 61-74. https://doi.org/10.1080/0034340052000320887

Breschi, S. \& Lissoni, F. (2001). Knowledge spillovers and local innovation systems: a critical survey. Industrial and Corporate Change, 10(4), 975-1005. https://doi.org/10.1093/icc/10.4.975

Brown, J.S. \& Duguid, P. (1991). Organizational learning and communities of practice: toward a unified view of working, learning and innovation. Organization Science, 2(1), 40-57. https://doi.org/10.1287/orsc.2.1.40

Burt, R.S. (2000). Decay functions. Social Networks, 22(1), 1-28. https://doi.org/10.1016/S0378-8733(99)00015-5

Camagni, R. (2017). Territorial capital, competitiveness and regional development. In: R. Huggins \& P. Thompson (eds.). Handbook of regions and competitiveness: contemporary theories and perspectives on economic development. Edward Elgar Publishing. https://doi.org/10.4337/9781783475018.00016

Capello, R. (1999). Spatial transfers of knowledge in high technology milieux: learning versus collective learning processes. Regional Studies, 33(4), 353-366. https://doi.org/10.1080/00343409950081211 
Capello, R., Caragliu, A. \& Nijkamp, P. (2011). Territorial capital and regional growth: Increasing returns in knowledge use. Tijdschrift voor economische en sociale geografie, 102, 385-405. https://doi.org/10.1111/j.1467-9663.2010.00613.x

Carayannis, E. G., \& Campbell, D. F. J. (2009). 'Mode 3' and 'quadruple helix': toward a 21st century fractal innovation ecosystem. International Journal of Technology Management, 46(3-4), 201-234. https://doi.org/10.1504/IJTM.2009.023374

Carayannis, E. G., \& Campbell, D. F. J. (2010). Triple helix, quadruple helix and quintuple helix and how do knowledge, innovation and the environment relate to each other? a proposed framework for a trans-disciplinary analysis of sustainable development and social ecology. International Journal of Social Ecology and Sustainable Development, 1(1), 41-69. https://doi.org/10.4018/jsesd.2010010105

Carayannis, E. G., \& Rakhmatullin, R. (2014). The Quadruple/Quintuple innovation helixes and smart specialisation strategies for sustainable and inclusive growth in Europe and beyond. Journal of the Knowledge Economy, 5(2), 212-239. https://doi.org/10.1007/s13132-014-0185-8

Cohen, W.M. \& Levinthal, D.A. (1990). Absorptive capacity: a new perspective on learning and innovation. Administrative Science Quarterly, 35(1), 128-152. https://doi.org/10.2307/2393553

D’Aspremont, C., \& Jacquemin, A. (1988). Cooperative and noncooperative R\&D in duopoly with spillovers. American Economic Review, 78(5), 1133-1137.

Etzkowitz, H., \& Leydesdorff, L. (2000). The dynamics of innovation: From national systems and 'mode 2' to a triple helix of universityindustry-government relations. Research Policy, 29(2), 109-123. https://doi.org/10.1016/S0048-7333(99)00055-4

Fombrun, C.J. (1982). Strategies for network research in organizations. The Academy of Management Review, 7(2), 280-291. https://doi.org/10.5465/AMR.1982.4285594

Freel, M.S. (2003). Sectoral patterns of small firm innovation, networking and proximity. Research Policy, 32(5), 751-770. https://doi.org/10.1016/S0048-7333(02)00084-7

Frenken, K., Van Oort, F., \& Verburg, T. (2007). Related variety, unrelated variety and regional economic growth. Regional Studies, 41(5), 685-697. https://doi.org/10.1080/00343400601120296

Gertler, M.S. (1995). 'Being there': proximity, organization, and culture in the development and adoption of advanced manufacturing technologies. Economic Geography, 71(1), 1-26. https://doi.org/10.2307/144433

Gnyawali, D. R., \& Park, B. (2009). Co-opetition and technological innovation in small and medium-sized enterprises: A multilevel conceptual model. Journal of Small Business Management, 47(3), 308-330. https://doi.org/10.1111/j.1540-627X.2009.00273.x

Gnyawali, D.R., \& Park, B. (2011). Co-opetition between giants: Collaboration with competitors for technological innovation. Research Policy, 40(5), 650-663. https://doi.org/10.1016/j.respol.2011.01.009

Granovetter, M.S. (1973). The strength of weak ties. American Journal of Sociology, 78(6), 1360-1380. https://doi.org/10.1086/225469

Hite, J. M., \& Hesterly, W. S. (2001). The evolution of firm networks: From emergence to early growth of the firm. Strategic Management Journal, 22(3), 275-286. https://doi.org/10.1002/smj.156

Knoben, J. \& Oerlemans, L.A.G. (2006). Proximity and inter-organizational collaboration: a literature review. International Journal of Management Reviews, 8(2), 71-89. https://doi.org/10.1111/j.1468-2370.2006.00121.x

Lane, P.J., \& Lubatkin, M. (1998). Relative absorptive capacity and interorganizational learning. Strategic Management Journal, 19(5), 461-477. https://doi.org/10.1002/(SICI)1097-0266(199805)19:5<461::AID-SMJ953>3.0.CO;2-L

Lave, J., \& Wenger, E. (1991). Situated learning, legitimate peripheral participation. Cambridge University Press: Cambridge. https://doi.org/10.1017/CBO9780511815355

Leborgne, D., \& Lipietz, A. (1988). New technologies, new modes of regulation: some spatial implications. Environment and Planning D: Society and Space, 6(3), 263-280. https://doi.org/10.1068/d060263 
The International Journal

ISSN 2345-0282 (online) http://jssidoi.org/jesi/

2018 Volume 5 Number 4 (June)

http://doi.org/10.9770/jesi.2018.5.4(22)

Leborgne, D., \& Llpietz, A. (1992). Conceptual fallacies and open questions on post-Fordism. In: M. Storper \& A.J. Scott (eds). Pathways to Industrialization and Regional Development, 332-348. London: Routledge.

Lechner, C., \& Dowling, M. (2003). Firm networks: External relationships as sources for the growth and competitiveness of entrepreneurial firms. Entrepreneurship and Regional Development, 15(1), 1-26. https://doi.org/10.1080/08985620210159220

Leontief, W. (1973). Input-Output Economics. New York: Oxford University Press.

Mattes, J. (2011). Dimensions of proximity and knowledge bases innovation between spatial and non-spatial factors. Regional Studies, 46(8), 1085-1099. https://doi.org/10.1080/00343404.2011.552493

Mikhaylov, A.S. (2016). An integrated approach to delimitation and demarcation of a spatial network boundary. International Journal of Economic Research, 13(7), 2719-2734.

Mikhaylov, A.S., \& Bolychev, O.N. (2015). Forms of transnational economic cooperation and integration in the Baltic region. International Journal of Economics and Financial Issues, 5(2), 55-64.

Mikhaylova, A.A., \& Mikhaylov, A.S. (2016). Re-distribution of knowledge for innovation around Russia. Int. J. Technological Learning, Innovation and Development, 8(1), 37-56. https://doi.org/10.1504/IJTLID.2016.075179

Murdoch, J. (1998). The spaces of actor-network theory. Geoforum, 29(4), 357-374. https://doi.org/10.1016/S0016-7185(98)00011-6

Normann, R., \& Ramirez, R. (1993). From value chain to value constellation: designing interactive strategy. Harvard business review, 71(4), 65-77.

OECD (2001). Territorial Outlook 2001, Organization for Economic Cooperation and Development, Paris

Perucca, G. (2014). The role of territorial capital in local economic growth: evidence from Italy. European Planning Studies, 22(3), 537562. https://doi.org/10.1080/09654313.2013.771626

Polenske, K. (2004). Competition, collaboration and cooperation: an uneasy triangle in networks of firms and regions. Regional Studies, 38(9), 1029-1043. https://doi.org/10.1080/0034340042000292629

Rugman, A.M., \& Verbeke, A. (2003). Multinational enterprises and clusters: an organizing framework. In: V. Mahnke, \& T. Pedersen (eds.). Governing Knowledge-Processes. Management International Review. vol 3. Gabler Verlag. pp. 151-169. https://doi.org/10.1007/978-3-322-90232-0_9

Storper, M. (1995). The resurgence of the regional economies ten years later: the region as a nexus of untraded interdependencies. European Urban and Regional Studies, 2(3), 191-215. https://doi.org/10.1177/096977649500200301

Tallman, S., Jenkins, M., Henry, N., \& Pinch, S. (2004). Knowledge, clusters, and competitive advantage. The Academy of Management Review, 29(2), 258-271. https://doi.org/10.5465/AMR.2004.12736089

Teece, D.J. (1998). Capturing value from knowledge assets: The new economy, markets for know-how, and intangible assets. California Management Review, 3, 55-79. https://doi.org/10.2307/41165943

Teece, D.J. (2007). Explicating dynamic capabilities: The nature and microfoundations of (sustainable) enterprise performance. Strategic Management Journal, 28(13), 1319-1350. https://doi.org/10.1002/smj.640

Torre, A. (2008). On the role played by temporary geographical proximity in knowledge transmission. Regional Studies, 42(6), 869-889. https://doi.org/10.1080/00343400801922814

Torre, A., \& Gilly, J.P. (2000). On the analytical dimension of proximity dynamics. Regional Studies, 34(2), 169-180. https://doi.org/10.1080/00343400050006087

Torre, A., \& Wallet, F. (2014). Regional development and proximity relations. Cheltenham: Edward Elgar. https://doi.org/10.4337/9781781002896 
The International Journal

ENTREPRENEURSHIP AND SUSTAINABILITY ISSUES

ISSN 2345-0282 (online) http://jssidoi.org/jesi/

2018 Volume 5 Number 4 (June)

http://doi.org/10.9770/jesi.2018.5.4(22)

Toth, B.I. (2014). Territorial capital: theory, empirics and critical remarks. European Planning Studies, 23(7). 1327-1344. https://doi.org/10.1080/09654313.2014.928675

Zaheer, A., \& Bell, G.G. (2005). Benefiting from network position: Firm capabilities, structural holes, and performance. Strategic Management Journal, 26(9), 809-825. https://doi.org/10.1002/smj.482

\section{Aknowledgements}

The reported study was funded by RFBR according to the research project 18-010-00015 "Models, effects, strategies and mechanisms of the inclusion of the western borderline of Russia into the system of horizontal interregional economic relations in the context of the Greater Eurasia"

Andrey MIKHAYLOV is the Deputy Vice-rector for research and international affairs of the Immanuel Kant Baltic Federal University and the senior research fellow at the Institute of Environmental Management, Urban Development and Spatial Planning, Kaliningrad, Russian Federation. Dr. Mikhaylov is the graduate of Karlstad University (Sweden) and holds a doctoral degree in human geography. His research is devoted to the issues of socio-spatial divergence, inter- and intraregional inequalities and spatially targeted regional policies.

ORCID ID: orcid.org/0000-0002-5155-2628

Copyright (C) 2018 by author(s) and VsI Entrepreneurship and Sustainability Center This work is licensed under the Creative Commons Attribution International License (CC BY). http://creativecommons.org/licenses/by/4.0/

c. (i) Open Access 